Tohoku J. exp. Med., 1973, 109, 385-406

\title{
Onset and Progress of Diabetic Glomerulosclerosis
}

\author{
Yuichi Yamauchi and Jinichi Suzuki \\ Department of Internal Medicine, Nagamachi Branch Hospi- \\ tal, Tohoku University School of Medicine, Sendai \\ Akira Ohneda and Shoichi Yamagata \\ The Third Department of Internal Medicine, Tohoku Univer- \\ sity School of Medicine, Sendai \\ Yoshio Gото \\ The Third Department of Internal Medicine, Hirosaki Univer- \\ sity School of Medicine, Hirosaki
}

\begin{abstract}
Yamauch, Y., Suzukt, J., OHneda, A., Yamagata, S. and Goto, Y. Onset and Progress of Diabetic Glomerulosclerosis. Tohoku J. exp. Med., 1973, 109 (4), 385406 - Clinicopathological investigations were made about the mode of the onset and progress of diabetic glomerulosclerosis; 206 renal biopsies were done on randomly selected 191 patients with various degrees of diabetic states. On 11 diabetics from whom renal biopsy specimens sufficient for histological examination could be obtained twice or three times, a prospective study was carried out by correlating morphological with clinical features during the periods of biopsies. The onset of diabetic glomerulosclerosis was not parallel with the progress; juvenile diabetics usually showed a lower incidence of diabetic glomerulosclerosis than adult-onset diabeties, whereas the progress of the disease was slower in adultonset diabetics than in juvenile ones in whom diabetic renal changes strikingly increased along with prolongation of diabetes. Diabetic glomerulosclerosis, at least in overt diabetes, is essentially irreversible in its nature, and the histological changes are closely correlated not only with blood sugar, but also with serum lipids and blood pressure levels. More or less remarkable discrepancy between the grade of morphological changes and clinical features is recognized, when the renal lesions are not so advanced. The prognosis of diabetic glomerulosclerosis depends necessarily on both clinical and morphological aspects, and repeated renal biopsies may serve to offer valuable information from the histopathological point.

diabetic glomeruloselerosis; diabetic nephropathy; renal biopsy
\end{abstract}

It is today a generally accepted view that diabetes mellitus is more and more frequently experienced with the progress of civilization in modern life. In Japan it cannot be an exception; it is estimated that her patients with diabetes mellitus now exceed 1.3 million including those with the latent condition. It is especially to notice that the frequency of the disease is high among those over 40 years of age; the frequency is $6.0 \%$ in men and $3.3 \%$ in women over 40 years. On the

Received for publication, October 3, 1972.

Address for reprints: Yuichi Yamauchi, M.D., Department of Internal Medicine, Nagamachi Branch Hospital, Tohoku University School of Medicine, 13-1, 5, Nagamachi, Sendai, Japan 
other hand, since the introduction of insulin by Banting and Best and of antibiotics, death due to coma and infections abruptly decreased, and the treatment remarkably extended the average life of diabetics. However, increasing death due to complication of vascular diseases has become the major concern at present.

The statistics of death of diabetic patients in Japan in 1967 indicate that the death due to cardio-renal vascular diseases attains $36.4 \%$ and ranks the top of all the fatal cases. It is nevertheless noteworthy that the percentage is much lower than $75.0 \%$ of United States (Kuzuya and Kosaka 1970). The difference may be attributed to difference of dietary life: Japanese people still take food rich in carbohydrates, although the Japanese dietary condition has been gradually westernized. Goto and Fukuhara (1968) recently published autopsy studies of cases collected from the Annual Reports of Autopsy Cases in Japan for the year 1958-1965; they demonstrated that nephropathy shared $17.7 \%$ of those with vascular disturbances in the fatal cases of primary diabetes; this offers a sharp contrast to the American statistics (Root 1965), which showed cardiac diseases as the top causative factor. In view of this tendency in Japan, further studies on the onset, progress, and prognosis of diabetic nephropathy seem to be important problems. A large number of clinicopathological studies have so far been made, particularly on the possible correlation of age, duration, and control of diabetes with the morphological renal changes (Johnsson 1960; Marble 1965; Berkman and Rifkin 1966; Bloom 1967; Marble 1967), but most of them have been retrospective studies with relatively small numbers of patients. Therefore, no definite conclusion has so far been drawn. In addition, cases with thickening of glomerular basement membranes have been detected more and more frequently in the stage of prediabetes or early diabetes (Camerini-Davalos et al. 1964; Camerini-Davalos 1966). The hereditary hypothesis has been supported by an increasing number of investigators who claim that vascular disturbances begin or develop independent of the metabolic defects in diabetes mellitus. This concept presents a sharp contrast to the conventional metabolic hypothesis (Daysog et al. 1961; Colwell 1964). It appears that the fundamental difference between the two hypotheses brings about confusions on the relationship between the control of diabetes mellitus and onset of disturbances in small blood vessels.

The present study was carried out with a number of renal biopsies in an attempt to re-examine whether or not the onset and progress of diabetic glomerulosclerosis are caused by the same factors, and whether or not they are in some way correlated with the control of diabetes mellitus. Furthermore, in an attempt prospectively to evaluate the onset and progress of diabetic glomerulosclerosis, repeated renal biopsies were conducted on the same patients as far as possible.

\section{Materials and Methods}

The subjects consisted of 191 patients admitted to the Third Dept. of Internal Medicine and Nagamachi Branch Hospital of Tohoku University, School of Medicine: 31 of them were those with juvenile diabetes of age less than 30 . The age distribution of the adult-onset diabetes was 28 in the $30 \mathrm{~s}, 28$ in the $40 \mathrm{~s}, 49$ in the $50 \mathrm{~s}$ and 55 in the $60 \mathrm{~s}$ and 
higher, showing the higher morbidity rate in aged people. The grade of the diabetic state varied considerably, but overt diabetes was found in the majority of the cases. The sex distribution of the patients was 102 males and 89 females. Of all these patients, 13 underwent renal biopsy twice with an interval of 1-5 years, and one was biopsied three times. Therefore, 206 renal biopsy specimens were obtained from 191 patients in the total. Most of the 14 patients who were submitted to repeated biopsies had poorly controlled diabetes mellitus and some of them received prolonged treatment owing to complications or were re-admitted on account of recurrences. However, three out of these cases were excluded from the present study, because in two of them a sufficient number of glomeruli could not be obtained and in the other the patient had an early complication of nephritis.

The renal biopsy was transdermally conducted with a Vim-Silverman needle and the specimen was fixed with acidified Zenker-formalin and embedded in paraffin to make semiserial sections. They were then stained with hematoxlin-eosin, periodic acid Schiff, Goldner's trichrome and Mallory's azan for histological studies. To express the severity of diabetic glomerulosclerosis, the histological findings were graded into four stages including 'nodular' and 'diffuse' lesions: the two histological types were regarded as representing different severity of qualitatively the same pathological process. In some of the patients of repeated biopsies, electron microscopic findings were also taken into consideration in the evaluation of morbid process. In order to express the morphological changes of diabetic renal lesions quantitatively, the IDGL (index of diabetic glomerular lesion) method proposed by Suwa (Suwa and Yamagata 1965) and Fukuhara (1968) was adopted; the principle of the method consists in grading the glomerular lesions according to mesangial thickening.

A variety of routine clinical tests were conducted in order to compare the clinical states with morphological features of the kidneys. The blood sugar level was determined with auricular blood by the method of Fujita and Iwatake (1931) and the glucose-oxidase method; the former method is nearly equivalent to the Hagedorn-Jensen's method. The effect of blood sugar control was rated by 'excellent' when in more than $80 \%$ of the cases of all the disease stages the blood sugar level was lowered below $100 \mathrm{mg} / 100 \mathrm{mI}$ in fasting time and by 'good' when blood sugar was $100-140 \mathrm{mg} / 100 \mathrm{ml}$, by 'fair' when it was $140-180 \mathrm{mg}$ / $100 \mathrm{ml}$ and by 'poor' when it was higher than $180 \mathrm{mg} / 100 \mathrm{ml}$. (The values determined with the glucose oxidase method were converted into those by the Fujita-Iwatake's method.)

The serum lipids were evaluated with venous blood. The total lipids were determined by Bragdon's method, while Zak-Henly's modified method, Van Handel's method, and Taussky's method were applied to determine the total cholesterol content, neutral fat content and phospholipid level respectively. The renal functions were evaluated from the results of GFR, RPF, PSP and BUN. The retinopathy was determined by the clinical examination of ophthalmological specialists. The neurological disturbances were examined not only by the general neurological tests but also by motor nerve conduction velocity of the ulnar nerve and threshold values of vibratory senses, so that a new standard of our own could be established.

In the evaluation of the above-mentioned renal biopsy special attention was paid to a dynamic analysis of diabetic glomerulosclerosis through comparison of the grade of the lesion with the duration of diabetes mellitus, blood sugar level and other clinical findings.

\section{Results}

\section{1) Onset of diabetic glomerulosclerosis}

It is a common knowledge that the frequency of diabetic glomerulosclerosis is influenced by the age of the patients or the duration of the disease. First of all, 206 renal biopsy specimens were evaluated in reference to the above-mentioned two factors. As shown in Table 1, the patients were divided into the three groups: young diabetic group of less than 39 years of age, adult diabetic group of $40-59$ 
TABLE 1. Effects of aging factor and duration of diabetes on incidence of diabetic glomerulosclerosis

(206 biopsy cases)

\begin{tabular}{|c|c|c|c|c|c|c|c|}
\hline \multirow{2}{*}{$\begin{array}{l}\text { Age } \\
(y)\end{array}$} & \multirow{2}{*}{$\begin{array}{l}\text { Duration of } \\
\text { diabetes }(y)\end{array}$} & \multicolumn{4}{|c|}{ Grade of diabetic glomerulosclerosis } & \multirow{2}{*}{$\begin{array}{l}\text { Percentage of diffuse } \\
\text { and nodular type } \\
\text { in total cases }(\%)\end{array}$} & \multirow{2}{*}{$\begin{array}{l}\text { Signifi- } \\
\text { cance }\end{array}$} \\
\hline & & None & $\begin{array}{l}\text { Slight } \\
\text { lesion }\end{array}$ & $\begin{array}{l}\text { Diffuse } \\
\text { lesion }\end{array}$ & $\begin{array}{l}\text { Nodular } \\
\text { lesion }\end{array}$ & & \\
\hline \multirow{3}{*}{$\sim 39$} & $\leqq 5$ & $\begin{array}{l}\text { cases } \\
21\end{array}$ & $\begin{array}{l}\text { cases } \\
21\end{array}$ & $\begin{array}{c}\text { cases } \\
7\end{array}$ & $\begin{array}{c}\text { cases } \\
2\end{array}$ & $9 / 51(18)$ & \multirow{3}{*}{$\begin{array}{l}{ }^{*} \mathrm{P}<.05 \\
-\dagger \mathrm{P}<.01\end{array}$} \\
\hline & $5 \sim 10$ & 0 & 7 & 3 & 4 & $7 / 14(50)$ & \\
\hline & $11 \sim$ & 0 & 0 & 1 & 2 & $3 / 3(100)$ & \\
\hline \multirow{3}{*}{$40 \sim 59$} & $\leqq 5$ & 7 & 15 & 12 & 9 & $21 / 53(40)$ & \multirow{3}{*}{$\ddagger \mathrm{P}<.01$} \\
\hline & $5 \sim 10$ & 1 & 3 & 5 & 8 & $13 / 17(76)$ & \\
\hline & $11 \sim$ & 2 & 2 & 2 & 5 & $7 / 11(64)$ & \\
\hline \multirow{3}{*}{$60 \sim$} & $\leqq 5$ & 11 & 6 & 15 & 7 & $22 / 39(56)$ & \multirow{3}{*}{ N.S. } \\
\hline & $5 \sim 10$ & 2 & 1 & 3 & 2 & $5 / 8(63)$ & \\
\hline & $11 \sim$ & 2 & 2 & 3 & 3 & $6 / 10(60)$ & \\
\hline
\end{tabular}

years of age, and the group of over 60 years of age. Each group was then subdivided for further examination into three sub-groups according to whether the duration of diabetes was less than 5 years, 5-10 years, or more than 11 years.

In the young diabetic group, the frequency of the specific diabetic glomerulosclerosis amounted to only $18 \%$ in the patients when the duration of the disease was less than 5 years, while those of 5-10 years' and more than 11 years' duration amounted respectively to 50 and $100 \%$, and the overall incidence in this age group was 19 of $69(28 \%)$. Significant differences in the incidence of glomerulosclerosis could be observed among these groups through the chi-square test. These results would mean that although the frequency of diabetic glomerulosclerosis is generally low in relatively young patients, the frequency increases steadily with the duration of diabetes mellitus and that in 10 years diabetic glomerulosclerosis can be established in most of the patients.

In the adult group of 40-59 years of age, the frequency reached $40 \%$ when the duration of the disease was less than 5 years, which was slightly higher than that in the younger group of the same disease duration. However, the patients of 5-10 years' duration of the disease showed a significant increase in glomerular involvement to $76 \%$, whereas that of the group of more than 11 years' duration was not more than $64 \%$. The overall frequency attained $51 \%$ or 41 out of 81 . This means that the overall frequency of the disease was higher than that of the younger group and that diabetic glomerulosclerosis can be established within relatively short periods. On the other hand, in patients older than 60 years and affected by senile diabetes mellitus, glomerulosclerosis occurred in a relatively high 
TABLE 2. Correlation of diabetic glomerulosclerosis with control of blood sugar levels Juvenile Diabetes (113 biopsy cases)

\begin{tabular}{|c|c|c|c|c|c|}
\hline $\begin{array}{l}\text { Duration of } \\
\text { diabetes }(y)\end{array}$ & $\begin{array}{l}\text { Control of } \\
\text { diabetes }\end{array}$ & $\begin{array}{c}\text { Nonspecific } \\
\text { change }\end{array}$ & $\begin{array}{l}\text { Specific } \\
\text { change }\end{array}$ & $\begin{array}{l}\text { Percentage of } \\
\text { specific change }\end{array}$ & Significance \\
\hline \multirow{3}{*}{$\leqq 5$} & Good & 4 cases & 0 cases & $0 \%$ & \multirow{3}{*}{ N.S. } \\
\hline & Fair & 4 & 1 & 20 & \\
\hline & Poor & 8 & 1 & 11 & \\
\hline \multirow{3}{*}{$5 \sim 10$} & Good & 2 & 1 & 33 & \multirow{3}{*}{ N.S. } \\
\hline & Fair & 2 & 0 & 0 & \\
\hline & Poor & 1 & 5 & 83 & \\
\hline
\end{tabular}

Adult-onset Diabetes

\begin{tabular}{|c|c|c|c|c|c|}
\hline \multirow{3}{*}{$\leqq 5$} & Good & 18 cases & 11 cases & $38 \%$ & \multirow{3}{*}{$* \mathrm{P}<.05$} \\
\hline & Fair & 6 & 7 & 54 & \\
\hline & Poor & 3 & 8 & 73 & \\
\hline \multirow{3}{*}{$5 \sim 10$} & Good & 2 & 4 & 67 & \multirow{3}{*}{ N. S. } \\
\hline & Fair & 2 & 7 & 78 & \\
\hline & Poor & 0 & 5 & 100 & \\
\hline \multirow{4}{*}{$>11$} & Good & 2 & 2 & 50 & \multirow{4}{*}{ N. S. } \\
\hline & Fair & 1 & 2 & 67 & \\
\hline & Poor & 1 & 3 & 75 & \\
\hline & & & & $=3.872$ & \\
\hline
\end{tabular}

ratio of $56 \%$ in the group of disease duration less than 5 years and that even the duration became extended, the frequency of the lesion remained nearly unchanged. The overall frequency of the aged group attained $58 \%$ or 33 out of 57 . In other words, this group was characterized by a higher overall frequency, but the glomerular lesions were hardly influenced by the duration of diabetes.

On the basis of the above results, the age and duration of diabetes seem to be of great importance in the onset of diabetic glomeruloselerosis, but the lesion may be influenced by successful control of the blood sugar levels. It is necessary simultaneously to evaluate the effect of blood sugar control with the age and duration of the disease. A reliable information about blood sugar control can be obtained only by repeated blood sugar determinations over a year. The condition was not always satisfied in all the biopsy cases of the present study. However, in 113 cases blood sugar control was regarded as successful according to the results shown in Table 2. Of all the 29 patients with juvenile diabetes mellitus, four with good control in the group of a disease duration less than 5 years showed no specific glomerulosclerosis, while the groups with fair and poor controls exhibited the specific changes in 20 and $11 \%$, respectively, but there was no statistically 
Table 3. Clinical data on 11 dixbetics; renal biopsy done twice or thrice

\begin{tabular}{|c|c|c|c|c|c|c|c|c|}
\hline No. & Cases & $\begin{array}{l}\text { Age at } \\
\text { first } \\
\text { admis- } \\
\text { sion }\end{array}$ & $\operatorname{Sex}$ & $\begin{array}{l}\text { Duration } \\
\text { of } \\
\text { diabetes }\end{array}$ & $\begin{array}{l}\text { Interval bet- } \\
\text { ween initial and } \\
\text { terminal biop- } \\
\text { sies }\end{array}$ & $\begin{array}{l}\text { Control } \\
\text { of } \\
\mathrm{FBS}^{*}\end{array}$ & $\begin{array}{l}\text { Thera- } \\
\text { py }\end{array}$ & Complications \\
\hline 1 & K.S. & $30 \mathrm{y}$ & M & $1 \mathrm{y} .6 \mathrm{~m}$. & $3 y$ & $\mathrm{~F}$ & $\mathrm{I}$ & Acromegaly \\
\hline 2 & K.A. & $25 \prime \prime$ & $\mathrm{F}$ & $4 y$ & $5 "$ & $\mathrm{P}$ & I & \\
\hline 3 & G.K. & $50 " \prime$ & M & $2 \mathrm{~m}$ & $5 \prime \prime$ & $\mathrm{F}$ & $\mathrm{I} \rightarrow \mathrm{O}$ & Gastric ulcer \\
\hline 4 & T.D. & $42 "$ & $\mathrm{~F}$ & $2 \mathrm{y}$ & $5 "$ & $\mathrm{P} \rightarrow \mathrm{F}$ & 0 & \\
\hline 5 & S.K. & $14 "$ & M & $\operatorname{lm}$. & $4 \prime \prime$ & $\mathrm{P} \rightarrow \mathrm{E}$ & $\mathrm{I} \rightarrow \mathrm{O}$ & \\
\hline 6 & T.M. & $27 "$ & M & $5 \mathrm{y} .5 \mathrm{~m}$. & $1.5 \prime \prime$ & $\mathrm{P}$ & I & Hemochromatosis \\
\hline 7 & T.T. & $24 " \prime$ & $\mathrm{F}$ & $5 y$ & $2 \prime \prime$ & $\mathrm{P}$ & $\mathrm{I}$ & Pulmonary tuberculosis \\
\hline 8 & M.H. & $59 \pi$ & $\mathrm{F}$ & $6 \mathrm{y} .6 \mathrm{~m}$ & $4 "$ & $\mathrm{P} \rightarrow \mathrm{G}$ & 0 & \\
\hline 9 & Y.M. & $13 "$ & $\mathrm{~F}$ & $2 \mathrm{~m}$ & $3 \prime \prime$ & $\mathrm{P} \rightarrow \mathrm{G}$ & I & \\
\hline 10 & T.S. & $36 "$ & M & $4 y$. & $1 " \prime$ & $\mathrm{F}$ & $\mathrm{I} \rightarrow \mathrm{O}$ & Pulmonary tuberculosis \\
\hline 11 & I.Y. & $68 "$ & $\mathrm{~F}$ & $4 y$. & $4 "$ & $\mathrm{~F}$ & $0 \rightarrow I$ & \\
\hline
\end{tabular}

* E: Excellent. G: Good. F: Fair. P: Poor. FBS: Fasting blood sugar.

$\dagger$ O: Oral hypoglycemic agent. I: Insulin

significant difference between the two. In the group of patients with a 5-10 years' duration, the frequency of specific renal lesions tended to increase; particularly noteworthy was a high rate of $83 \%$ in the poor control group. On the other hand, in the group of adult-onset diabetes, the frequency of specific renal lesions attained $38 \%$ in the good control group, while the fair control group and the poor control group showed high frequencies of $54 \%$ and $73 \%$ respectively. The difference between the good control and the poor control groups was statistically significant.

It may be therefore claimed that the onset of glomerulosclerosis in the adult diabetics with relatively short morbid periods depends on the control of diabetes mellitus. In the two groups of durations of 5-10 years and of more than 10 years, a trend to increase in the onset of specific renal lesions could be noticed in those of poor control, although the result was statistically not endorsed. On the other hand, specific diabetic glomerulosclerosis was found in 17 cases of a known disease duration within 1 year and in 10 cases or $59 \%$ of the poor control group, whereas in cases over 10 years of the disease duration, 10 had nonspecific glomerulosclerosis, 8 or $80 \%$ of which the control of diabetes was regarded as 'good'. These results seem to imply that the onset of diabetic glomerulosclerosis is strongly influenced by the control of diabetes.

The above-mentioned results are summarized as follows: in the group of relatively young diabetics, the frequency of diabetic glomerulosclerosis is generally low, but it rapidly increases with the duration of diabetes almost without any correlation with the effect of blood sugar control. On the other hand, glomerulosclerosis in diabetics of adult-onset type is not only related to the disease duration, but also, or even more distinctly, susceptible to the diabetic controls; this is worthy of emphasis.

\section{2) Progress of diabetic glomerulosclerosis}

The progress of diabetic glomerulosclerosis has not so intensively studied as 
that of retinopathy which is one of the similar types of microangiopathy, because continuous observations of the lesion over a certain period are not always easy in human beings. In this section the conditions aggravating once initiated changes of glomerulosclerosis are discussed, based on comparisons of renal biopsies repeated in several years on the same patients and the clinical patterns in the same periods.

Table 3 demonstrates the clinical patterns of the cases of repeated renal biopsies. They are made of 6 young diabetics and 5 adult-onset ones with sex distribution of 5 males and 6 females. The duration of their disease was variable: some of them were admitted soon after the detection of diabetes and the maximum duration was 6.5 years. The control of diabetes on their first admission was estimated at 'fair' or 'poor'; they had all rather severe diabetes. In most of them insulin therapy was necessary. In some patients, when the effect of insulin was fair, the injection could be replaced by oral antidiabetic drugs. They had primary diabetes except for two patients who had secondary diabetes due to hemochromatosis and acromegalia. The interval of two renal biopsies was $1-5$ years, with an average of 3.4 years.

As shown in Table 4, the initial renal lesions of the 11 patients were mostly nonspecific in character except for two cases each of which had diffuse or nodular types of specific glomerulosclerosis. However, the second renal biopsy after varying intervals revealed the following results: in one of the patients the glomerular lesion proceeded to the nodular type which was also confirmed by the third renal biopsy. In Cases 1 and 2 the patients died soon after the last renal biopsy. The findings of their first and second biopsies are expressed with IDGLs in Table 4. Ten out of 11 exhibited increase in IDGLs, of which 7 showed significant changes. The sum of the average values and the standard errors in the differences in IDGL $(\triangle \mathrm{IDGL})$ of all the examined cases was $+0.62 \pm 0.19$ with a significance of $\mathrm{P}<$ $2.5 \%$. This means that the mesangial change in glomerulosclerosis advances steadily with the duration of diabetes, if the disease is severe enough. In other words, it is concluded that glomerulosclerosis in the diabetes is an irreversible change, since a tendency toward significant decrease in the IDGLs was observed in none of the cases.

In order to compare the developments of the above-mentioned morphological changes with other clinical neurovascular complications, the development of clinical symptoms is illustrated: abrupt aggravation of the clinical symptoms is shown with doulbe circles and moderate aggravation is indicated with dark circles, while white circles and (-) represent improved and unchanged symptoms. In the patients with rapidly progressive glomerulosclerosis as Nos. 1 and 2, rapid clinical aggravation was also observed in parallel. It is quite natural that the renal functions were deteriorated with advancing glomerulosclerosis. Particularly noteworthy was further the progress of retinopathy and neuropathy in a speed comparable with that of renal changes. In the group of aggravated glomerulosclerosis covering Nos. 3 though 7 , it was observed that the higher $\triangle$ IDGLs were, the more distinct was the tendency of their clinical symptoms toward deterioration. In 
TABLE 4. Interrelation with development of diabetic

\begin{tabular}{|c|c|c|c|c|}
\hline No. & $\begin{array}{l}\text { Progress of } \\
\text { renal involvement }\end{array}$ & $\begin{array}{l}\text { Histological } \\
\text { findings* }\end{array}$ & $\begin{array}{c}\mathrm{IDGL} \\
(\mathrm{M} \pm \mathrm{SE})\end{array}$ & Albuminuria ${ }^{++}$ \\
\hline 1 & \multirow{2}{*}{$\begin{array}{l}\text { Rapidly } \\
\text { progressed }\end{array}$} & $(-) \rightarrow D$ & $\begin{array}{r}0.21 \pm 0.09 \\
\rightarrow 1.95 \pm 0.08^{\dagger}\end{array}$ & - \\
\hline 2 & & $\mathrm{~S} \rightarrow \mathrm{D} \rightarrow \mathrm{N}$ & $\begin{aligned} & 1.07 \pm 0.13 \\
& \rightarrow 2.77 \pm 0.04^{\dagger}\end{aligned}$ & $\odot$ \\
\hline 3 & \multirow{5}{*}{ Deteriorated } & $\mathrm{S} \rightarrow \mathrm{D}$ & $\begin{array}{r}0.87 \pm 0.12 \\
\rightarrow 1.84 \pm 0.06\end{array}$ & - \\
\hline 4 & & $(-) \rightarrow D$ & $\begin{aligned} 0.66 & \pm 0.08 \\
\rightarrow 1.58 & \pm 0.06\end{aligned}$ & 0 \\
\hline 5 & & $(-) \rightarrow(-)$ & $\begin{array}{r}0.30 \pm 0.08 \\
\rightarrow 0.81 \pm 0.05^{\dagger}\end{array}$ & - \\
\hline 6 & & $(-) \rightarrow(-)$ & $\underset{\rightarrow 0.93 \pm 0.11}{0.53 \pm 0.11} \uparrow$ & 0 \\
\hline 7 & & $\mathrm{D} \rightarrow \mathrm{D}$ & $\underset{\rightarrow 1.79 \pm 0.04^{\ddagger}}{1.50 \pm 0.10}$ & - \\
\hline 8 & \multirow{4}{*}{ Unchanged } & $\mathrm{N} \rightarrow \mathrm{N}$ & $\begin{array}{r}2.30 \pm 0.13 \\
\rightarrow 2.50 \pm 0.18\end{array}$ & 0 \\
\hline 9 & & $(-) \rightarrow(-)$ & $\begin{array}{r}0.25 \pm 0.06 \\
\rightarrow 0.35 \pm 0.07\end{array}$ & - \\
\hline 10 & & $\mathrm{D} \rightarrow \mathrm{D}$ & $\begin{array}{r}2.16 \pm 0.07 \\
\rightarrow 2.14 \pm 0.14\end{array}$ & 0 \\
\hline 11 & & $\mathrm{~N} \rightarrow \mathrm{D}$ & $\begin{array}{r}2.18 \pm 0.15 \\
\rightarrow 2.20 \pm 0.10\end{array}$ & 0 \\
\hline
\end{tabular}

* (-) None. S: Slight lesion. D: Diffuse lesion. $N$ : Nodular lesion. $\dagger P<.001 . \ddagger P<.01$.

some cases, however, clinical symptoms had remained unchanged or even been improved in regard to neuropathy. In the cases of glomerulosclerosis covering Nos. 8 through 11, none except No. 11 which developed retinopathy, showed aggravation of clinical patterns; in most of them the symptoms were rather improved.

From the results of Tables 3 and 4, the progress of glomerulosclerosis was further evaluated in this paragraph in connection with the control of diabetes mellitus. In Nos. 1 and 2 which developed rapidly progressing renal lesions blood lipids and blood sugar were poorly controlled throughout their courses of disease; they were of juvenile type of diabetes mellitus really refractory to treatments. In the group of relatively advanced renal lesions, all except for No. 5 of improved blood sugar level showed also poor blood sugar control. The 5 patients included three of the juvenile type. In contrast, in 4 patients including two of the senile type of diabetes without advanced glomerulosclerosis, the control of diabetes upon their first admission was certainly poor, but subsequent control was kept successful. These results suggest that unsuccessful control of diabetes acts as an important 
glomerulosclerosis and changes of clinical states

\begin{tabular}{|c|c|c|c|c|c|c|}
\hline $\begin{array}{l}\text { Renal dys- } \\
\text { function }\end{array}$ & Edema & $\begin{array}{l}\text { Hyper- } \\
\text { tension }\end{array}$ & $\begin{array}{l}\text { Hyper- } \\
\text { lipemia }\end{array}$ & $\begin{array}{l}\text { Abnormali- } \\
\text { ty of ECG }\end{array}$ & $\begin{array}{l}\text { Retino- } \\
\text { pathy }\end{array}$ & $\begin{array}{l}\text { Neuro- } \\
\text { pathy }\end{array}$ \\
\hline - & - & - & - & - & $\odot$ & $\odot$ \\
\hline \multirow[t]{2}{*}{$\odot$} & $\odot$ & $\odot$ & - & $\bullet$ & $\odot$ & $\odot$ \\
\hline & - & - & 0 & - & - & - \\
\hline - & - & - & - & $\bullet$ & - & - \\
\hline- & - & - & 0 & - & - & 0 \\
\hline- & - & - & & - & - & 0 \\
\hline- & - & - & 0 & - & 0 & 0 \\
\hline \multirow[t]{3}{*}{0} & - & - & - & 0 & 0 & 0 \\
\hline & - & - & - & - & - & 0 \\
\hline & - & - & - & - & 0 & - \\
\hline & - & - & 0 & - & $\bullet$ & 0 \\
\hline
\end{tabular}

$++\ldots$ : No change. $\bigcirc$ Amerioration.

Deterioration. Marked deterioration.

accelerating factor toward the development of glomerulosclerosis.

3) Morphological characteristics of aggravated and stationary cases of diabetic glomerulosclerosis

This paragraph deals with the morphological characteristics of the cases of typical progress as well as of arrest of the disease examined by renal biopsy.

In Case 2 of rapid aggravation in a relatively short period, relatively mild mesangial changes and focal thickening of Bowman's capsule were observed at the first biopsy, but the structure of glomerular capillary loops was maintained in such a good condition that the lesion could not yet be termed even as diffuse type, the IDGL being $1.07 \pm 0.13$. However, hyalinosis of the efferent artery in Fig. 1-(a) suggests strongly the diabetic nature of this rather slight glomerular lesion. The Fig. 1-(b) demonstrates the second biopsy two years later; the thickening of mesangium was found spreading in a diffuse pattern to such an extent as to warrant a diagnosis of diffuse lesion of Bell. Some findings also suggest incipient capillary thrombosis. This also indicates progressive renal disturbances. In the 
rightmost bottom of the figure, marked hyalinosis of the efferent vessel was observed and the IDGL attained $2.01 \pm 0.16$. Fig. $1-($ c) illustrates the renal biopsy 31 months later. The period of biopsy corresponded to the stage of marked clinical renal insufficiency, and highly advanced renal lesions have undoubtedly caused glomerular insufficiency as comprihensible from a morphological viewpoint. Namely, infiltration of plasma components mixed with a number of fat droplet was detected in typical large and edematously swollen nodules; this could be regarded as representing a relatively early stage of nodule formation. Most of the capillary loops were found to have already been destroyed. The IDGL was as high as $2.77 \pm 0.04$. This patient died of renal insufficiency 17 months after the last renal biopsy, and the total clinical course was about 10 years since the onset of diabetes mellitus. Morphologically, we could pursue the development fairly well covering a period of about 5 years during which the patient developed initial mild renal impairment followed by rapidly progressing nodular lesions.

In Case 4 in which the renal lesions steadily advanced with poor control of blood sugars, only partial and mild thickening of mesangium was seen in the first renal biopsy as shown in the Fig. 2-(a), a nonspecific change with an IDGL of $0.66 \pm 0.08$. Further electron microscopic observation of this case could hardly yield any changes indicating renal functional disturbances; the average value of the minimum thickness of the glomerular capillary basement membrane was 3,400 $\pm 80 \mathrm{~A}$. In the second renal biopsy 5 years later as shown in the Fig. $2-(\mathrm{b})$, more advanced lesions could be seen such as diffuse thickening of the mesangium and formation of small hyaline crescents in the sub-capsular space. Electron microscopic observation revealed an increase in the mesangial matrix, but the minimum thickness of the capillary basement membrane amounted to $3,500 \pm 70 \AA$. The major site of the glomerular lesions was found in the mesangium. The IDGL rose up to $1.58 \pm 0.06$.

In the following two cases of senile diabetes no renal lesions were found to develop, unlike in the above-mentioned two cases.

Fig. 3 illustrates a glomerulus of Case 11 in which the disease remained stationary despite poor control of diabetes. In Fig. 3-(a), a number of capillary thromboses gradually obliterate the glomerulus. This is, however, a fortuitous change. The major part of the glomeruli exhibited diffuse lesions as shown in Fig. 3-(b). In view of hyalinosis of the efferent artery, the glomerular lesions of

Fig. 1. Renal involvement of a juvenile diabetic (Case 2).

Note relatively rapid progress of diabetic glomerulosclerosis.

(a) 1st biopsy (May, 1964).

Slight diabetic change with hyalinosis of vas afferens IDGL $=1.07 \pm 0.13$.

(b) 2nd biopsy after two years.

Diffuse type of diabetic glomerulosclerosis with beginning capillary thrombosis. In lower right part, typical hyaline thickening of vas efferens is detectable IDGL $=$ $2.01 \pm 0.16$.

(c) 3rd biopsy three years after the 2nd biopsy.

Enormously large nodules are developed in a glomerulus resulting in severe capillary collapse $\mathrm{IDGL}=2.77 \pm 0.04$. 


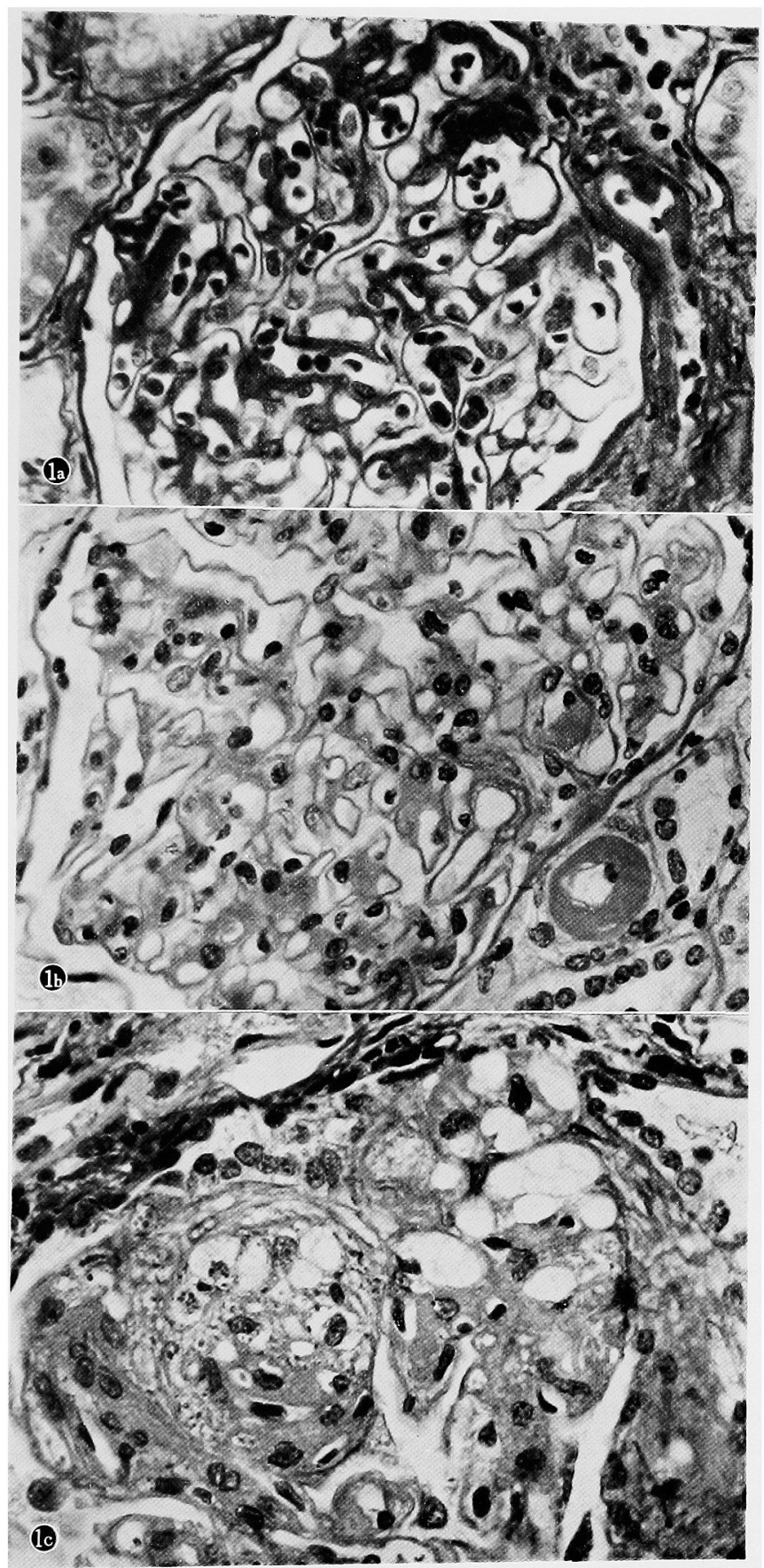




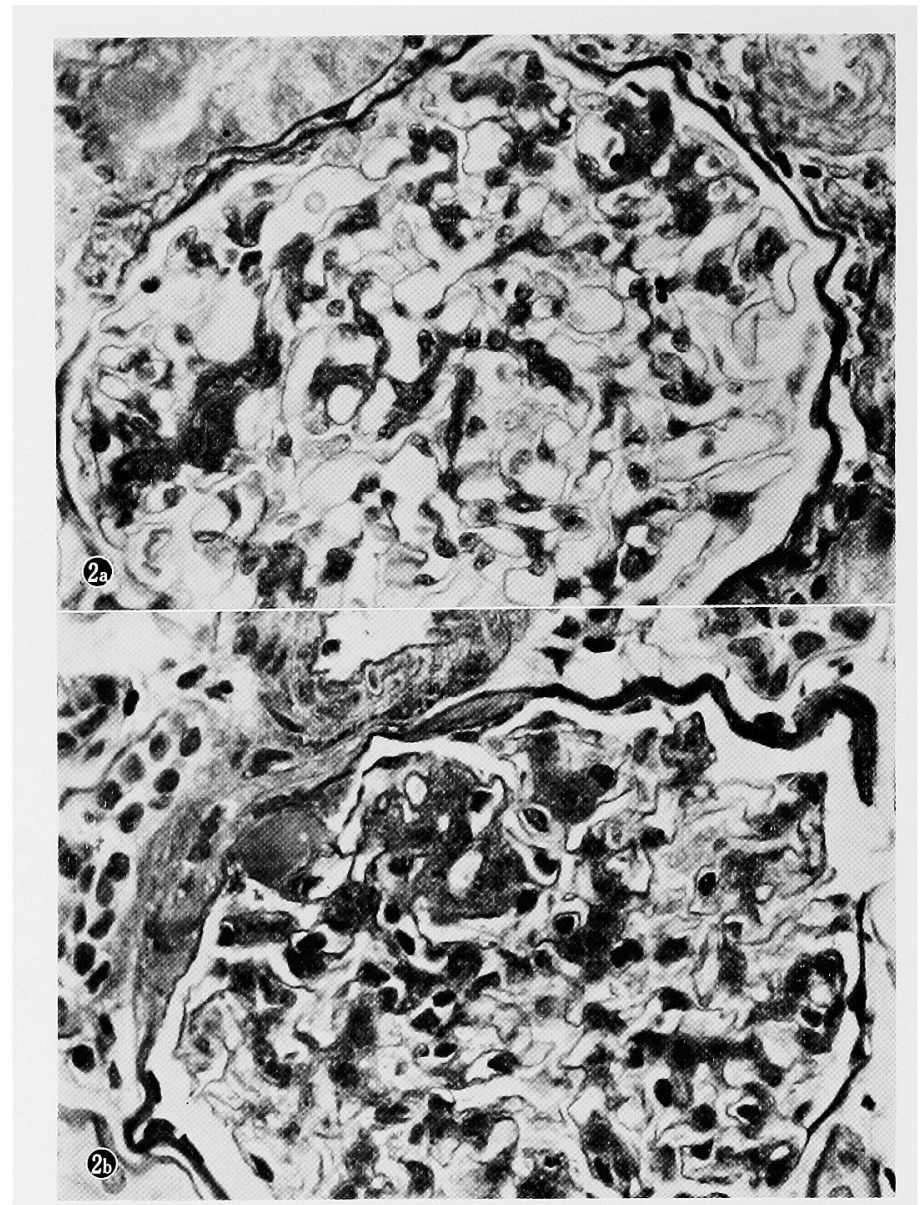

Fig. 2. Histological findings in a case of poor control of diabetes.

Note distinet progress of the glomerular changes (Case 4).

(a) Initial biopsy (July, I964).

No specific diabetic change detected IDGL $=0.66 \pm 0.08$.

(b) 2 nd biopsy after five years.

More advanced hyaline thickening of mesangial tissues with a single small hyaline nodule near subcapsular region.

$\mathrm{IDGL}=1.58 \pm 0.06$.

Fig. 3. An old diabetic with diffuse lesion.

Note relatively stable histological findings through the course of diabetes despite fair control of the disease (Case 11).

(a) Initial biopsy (Jan. 1966).

One of glomeruli showing glomerular collapse with multiple capillary thrombosis.

(b) Diffuse type of glomerulosclerosis and hyalinosis of Vas efferens is demonstrated (the same stage of biopsy).

$\mathrm{IDGL}=2.18 \pm 0.15$.

(c) 2nd biopsy after four years.

Diffuse lesion without nodular formation.

The structure of glomerular capillaries is still well preserved.

IDGL $=2.20 \pm 0.1$. 


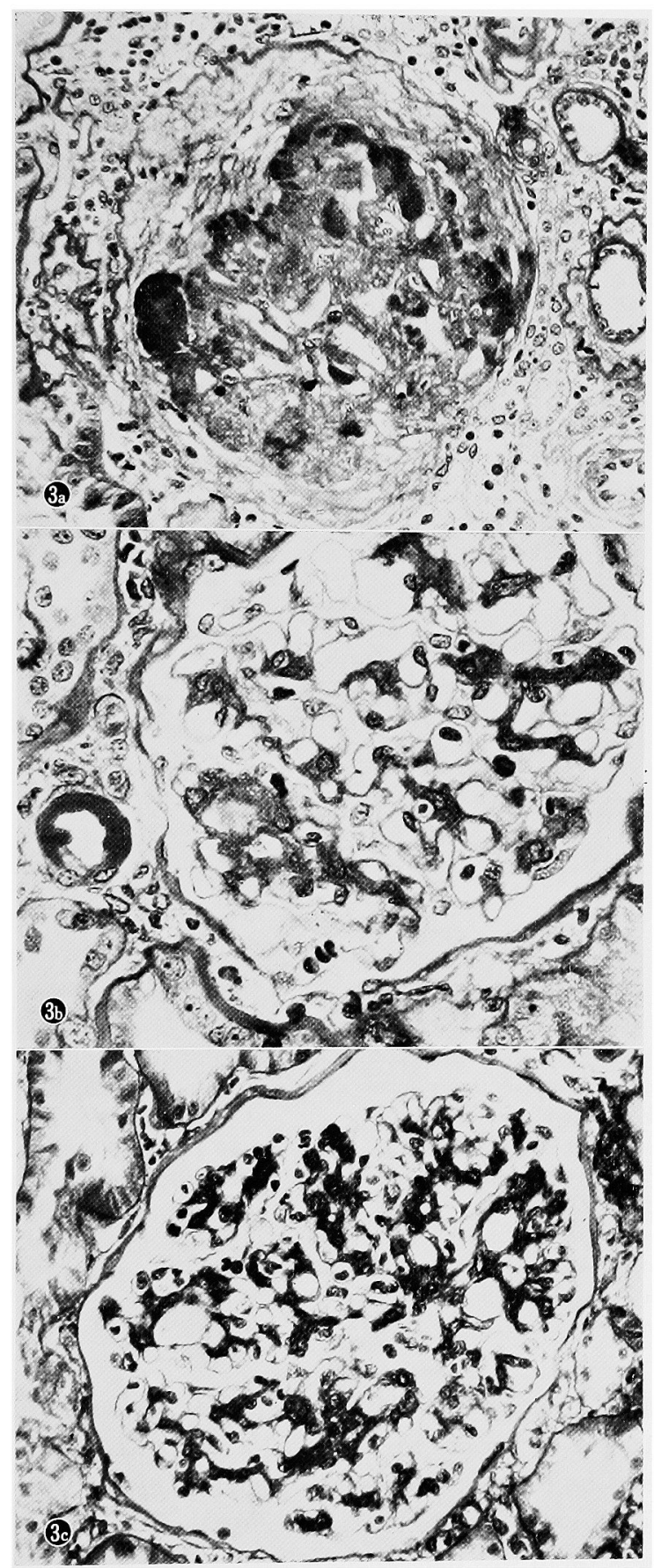




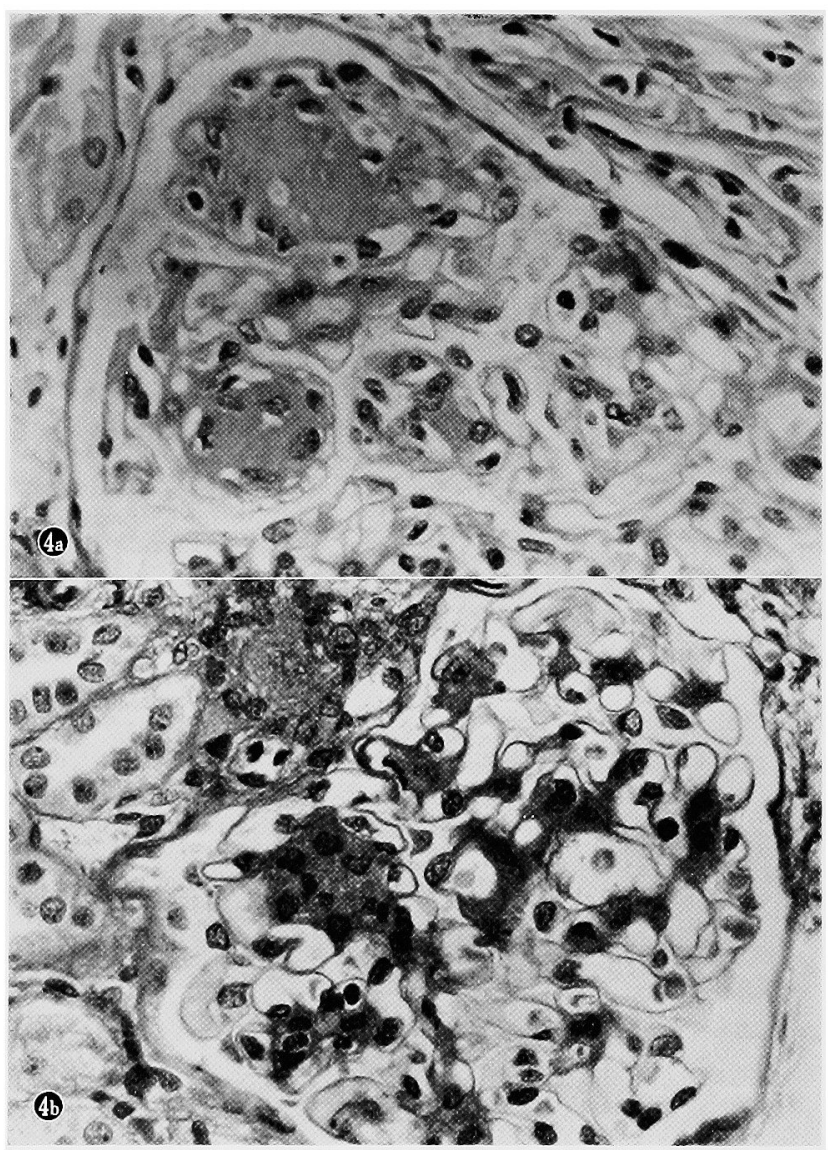

Fig. 4. Nodular lesion of Kimmelstiel-Wilson in an old diabetic with good diabetic control. Note almost the same nodular form without conspicuous capillary transformation at both periods (Case 8 ).

(a) Initial biopsy (Aug. 1963).

Relatively large nodules on a basis of diffuse type of diabetic glomerulosclerosis are demonstrated. $\mathrm{IDGL}=2.3 \pm 0.13$.

(b) 2nd biopsy after four years, rather atrophic nodule demonstrating mesangial scar formation. $\mathrm{IDGL}=2.5 \pm 0.18$

this case was regarded as specific glomerulosclerosis without structural impairment of capillary loops. The second biopsy after 4 years is shown in Fig. 3-(c). In this picture there is no essential difference in the finding from the first biopsy. The IDGLs were $2.18 \pm 0.15$ and $2.20 \pm 0.1$ in the first and second biopsies respectively. The result suggests there was neither deterioration nor improvement of renal function, and symptoms were stabilized.

Fig. 4 illustrates glomerular findings from a Case 8 of a well-controlled senile diabetic. In Fig. 4-(a), typical nodular changes on diffuse lesion are demonstrated, 
but there is hardly any structural damage in the capillary loops. By contrast, in the renal biopsy four years later as shown in the Fig. 4-(b), the nodules were reduced to smaller sizes and were strongly stained bluish by Mallory's azan staining, suggesting the scar formation from mesangial lesions. The IDGLs amounted to $2.3 \pm 0.13$ and $2.5 \pm 0.18$ in the first and second biopsies respectively, so that no progress of renal lesions seemed to have taken place. In this case, proteinuria was observed upon the first admission, but it diminished since the second admission and a very good clinical state could be maintained in the meantime.

\section{4) Prognosis of diabetic glomerulosclerosis}

The outcome of diabetic glomerulosclerosis is a question of clinical interests. Comparative study was made in this connection between the clinical patterns and the direct causes of death in 23 fatal cases in which renal biopsies had been possible. They were classified by the degrees of renal lesions. As shown in Table 5, most of them died in relatively short periods and $90 \%$ of the direct cause of death in patients with the nodular type renal lesions was renal insufficiency. Diffuse lesion could be found in about a half of them. In 5 cases of non-specific renal lesions, only one died of renal insufficiency, while most of the others died of malignant tumor or cerebrovascular disturbances. This naturally means that the more serious the glomerulosclerosis is, the greater is the tendency toward renal insufficiency and the worse is the prognosis. In addition, most of the cases of specific renal lesion had persistent proteinuria, and the complications such as retinopathy and hyperlipemia were by far more frequent.

Careful control of the patients was continued even after discharge from the special ambulatory clinic for the diabetics and exact evaluation of the prognosis was also made every year on the basis of questionnaires. The result indicates that an overwhelming number of patients in the group with specific glomerulo-

TaBle 5. Cause of death and clinical features in fatal cases of diabetes

\begin{tabular}{|c|c|c|c|c|}
\hline & \multirow[b]{2}{*}{ Clinical features } & \multicolumn{3}{|c|}{ Grade of diabetic glomerulosclerosis } \\
\hline & & $\begin{array}{c}\text { Nonspecific lesion } \\
(5 \text { cases })\end{array}$ & $\begin{array}{l}\text { Diffuse lesion } \\
\text { (8 cases) }\end{array}$ & $\begin{array}{l}\text { Nodular lesion } \\
\text { (10 cases) }\end{array}$ \\
\hline & $\begin{array}{l}\text { Mean duration } \\
\text { of diabetes }\end{array}$ & $11 \mathrm{y}$ & $8 \mathrm{y}$ & $8 \mathrm{y}$ \\
\hline \multirow{2}{*}{$\begin{array}{l}\text { Cause } \\
\text { of } \\
\text { death }\end{array}$} & Renal insufficiency & $1(20 \%)$ & $4(50 \%)$ & $9(90 \%)$ \\
\hline & Others & $4\left(80^{\prime \prime}\right)$ & $4(50 ")$ & $1\left(10^{\prime \prime}\right)$ \\
\hline \multirow{2}{*}{$\begin{array}{c}\text { Albumi- } \\
\text { nuria }\end{array}$} & Persistent & $2\left(40^{\prime \prime}\right)$ & $6\left(75^{\prime \prime}\right)$ & $9\left(90^{\prime \prime}\right)$ \\
\hline & Intermittent & $2\left(40^{\prime \prime}\right)$ & $1\left(13^{\prime \prime}\right)$ & $0\left(0^{\prime \prime}\right)$ \\
\hline \multicolumn{2}{|c|}{ Retinopathy } & $3(60 ")$ & $8(100 ")$ & $8(100 \prime)$ \\
\hline \multicolumn{2}{|c|}{ Hyperlipemia } & $2\left(50^{\prime \prime}\right)$ & $4\left(50^{\prime \prime}\right)$ & $7\left(70^{\prime \prime}\right)$ \\
\hline
\end{tabular}


sclerosis cannot return to their previous social lives and about $21 \%$ are unable to resume their works.

\section{Discussion}

Since Kimmelstiel and Wilson (1936) first described the renal glomerular changes specific to diabetes as 'nodular lesion', a large number of studies have been carried out on this problem (Bloodworth 1968). It is today generally accepted from a histopathological viewpoint that only this nodular type of Kimmelstiel and Wilson is diagnostic. The diffuse type of diabetic glomerulosclerosis described by Bell (1942) is not always specific to diabetes, because quite similar lesions are observed occasionally in other renal diseases, especially in mild chronic glomerulonephritis. However, Fukuhara (1968) proposed an affective method for the discrimination of diabetic lesions in histometrical analysis of diabetic kidneys. He stated that mesangial thickening in the glomerulus without corresponding nuclear increase was almost characteristic of diabetic nephropathy. According to Fukuhara's investigation, the mesangial tisue is a very sensitive portion in the glomerulus, where repeated plasmal infiltration and deposition are supposed to take place, and therefore mesangial thickening occurs even in the physiological condition and progresses with advancing ages. Bergstrand and Bucht (1964) regarded the mesangial cells as a group of reticulum cells, but the metabolic process or function in the mesangial area is still obscure. As most workers believe (Osterby 1971), increase in the mesangial volume without corresponding increase in the number of nuclei is one of the most fundamental histological changes in the diabetic kidney, as well as the thickening of the glomerular capillary basement membranes. On the other hand, some other vascular changes characteristic of diabetes, such as hyaline changes of the afferent or efferent arterioles, or pronounced sclerosis of intrarenal arterial branches are not infrequently observed. Moreover, in the advanced stage of diabetes the pathological features of the kidney are frequently complicated with superimposed pyelonephritis or hypertensive renal diseases. It is therefore not necessarily reasonable to regard the mesangial thickening as the sole index of diabetic renal damage. However, the glomerular changes give the most reliable information about the diabetic renal involvement even in a limited area of renal biopsy specimens. As was mentioned by Fukuhara, it would be justified to classify diabetic glomerulosclerosis into the following four types as 'none', 'slight', 'diffuse', and 'nodular'. So-called 'exsudative lesion' was a.iso included in the nodular lesion, because this type of glomerular lesion was in reality multiple capillary thrombosis, which often led to the nodular type.

It has been generally accepted that diabetic glomerulosclerosis seldom appears in juvenile patients, but its incidence and severity increase steadily with age (Knowles 1970; Rifkin and Berkman 1970). The tendency is likewise experimentally evidenced with Chinese hamsters (Shiral et al. 1967) and KK mice (CameriniDavalos et al. 1970). The above-mentioned aging process seen in the mesangial tissues would be partly responsible for the acceleration of the pathological process. 
Fukuhara demonstrated that slight glomerular lesions with low IDGLs are distributed widely in the total diabetic population irrespective of age, but higher IDGLs are detected mainly among adults of over 40 years of age. He also mentioned that a 7 years' or longer duration of diabetes was necessary to precipitate severe diabetic glomerulosclerosis. In addition, our statistical examinations also demonstrate that the frequency of diabetic glomerulosclerosis is low in juvenile diabetics, but high in adults over 40 years of age. Among the diabetics of over 10 years' duration, however, adult-onset diabetics show a lower incidence of diabetic glomerulosclerosis than juvenile diabetics do. The result corresponds to that of Gellman and his colleagues (1959). Although the patients may die of other diseases before full development of the renal lesion in the case of later onset of diabetes, it is still obvious that the greater prevalence of diabetic glomerulosclerosis among juveniles after long duration and its lower incidence among adult onset diabetics are characteristic clinical aspects.

Is there no other factor influencing the onset and progress of diabetic glomerulosclerosis except aging and the duration of diabetes? Ellenberg's (1962) report of three cases deals with rare types of classical Kimmelstiel and Wilson's lesion in the absence of clinical diabetic symptoms, but his comment that diabetic glomerulosclerosis develops independent of hyperglycemia seems controversial, because such an outcome is not yet generally accepted. The present authors do not think it appropriate to correlate the effect of diabetic control in relatively short periods directly before renal biopsy or autopsy with renal involvement, because blood sugar level may be occasionaly lowered in the terminal stages of diabetic glomeruloselerosis as a result of renal dysfunction. Careful examinations are necessary to determine the clinical factors influencing the renal involvement, and at least several years' follow-up soon after the detection of diabetes is indispensable. In our experience, more or less marked discrepancy between diabetic glomerulosclerosis and corresponding clinical signs is inevitable. Only $82 \%$ of diabetic glomerulosclerosis at most can be correctly diagnosed how elaborate the diagnostic criteria from clinical symptoms may be. An exact diagnosis is possible only by means of renal biopsy. Nodular glomerulosclerosis in a non-diabetic patient, recently described by Harrington and his colleagues (1966), and documented by their intensive follow-up study seems to be one of the exceptional cases suggesting that diabetic glomerulosclerosis develops independent of duration and/ or control of diabetes. The present authors have not their own experience of such cases, so that the conclusion of diabetic neplaropathy in the absence of overt diabetes cannot yet be sustained.

Since diabetic microangiopathy was thought to occur commonly in a majority of organs in the prediabetic stage (Siperstein et al. 1968) or subclinical diabetes (Johansen 1969), some investigators have proposed the current concept that the onset and progress of diabetic microangiopathy are not directly caused by metabolic defects in diabetes. Even if a slight form of diabetic microangiopathy can be recognized prior to overt metabolic disturbances of carbohydrate in diabetes 
mellitus, its progress does not always occur in the course of diabetes. This concept is supported by the authors' own results in which the frequency of diabetic glomerulosclerosis was approximately 60 to $70 \%$. These results indicate that the onset and progress of diabetic glomerulosclerosis are determined by different factors.

Some workers (Joslin et al. 1959) said that insufficient diabetic control played an important role in the pathogenesis of diabetic microangiopathy as well as the aging factor and the duration of diabetes. Marble (1965) considered that adequate treatments of diabetes might at least delay or retard the development of microangiopathy. Furthermore, he noted that microangiopathy could progress and regress in the prediabetic stage or chemical diabetes, and he emphasized the possibility of preventing the onset of microvascular disease or the progress of once developed microangiopathy by controlling the metabolic abnormalities in these stages. Our results show that the poorer the diabetic control, the higher the incidence of diabetic glomerulosclerosis, especially in adult-onset diabetes of short duration; therefore, the effective metabolic control during early periods of diabetes would probably influence the fate of diabetic glomerulosclerosis. Knowles (1970) noted that a poor control of diabetes alone would not be an initiating or promoting factor of systemic microangiopathy. The authors do not entirely deny primary high vulnerability of small vessels in some cases of diabetics. However, hormonal derangements seem to be still more important as one of the exogenous factors precipitating microangiopathy, because none of the genetic traits specific for diabetic vascular disturbances has as yet been ascertained.

Long-term follow-up study made by Hatch and his colleagues (1961) demonstrated that coexistence or shift of diffuse and nodular renal lesions had been observed in glomeruli of the same diabetic patient, and that the two types of renal lesions are to distinguish in their pathogenesis. However, the authors cannot accept the concept, because the nodular type of renal lesions developed on the background of diffuse lesions in general. Moreover, it was demonstrated in Case 2 by repeated renal biopsies that the nodular lesions ensued upon diffuse ones. This case also exhibited renal morphological changes which appeared to run fairly parallel with clinical states, especially with the control of diabetes. On the other hand, much insulin was necessary in this case probably partly on account of insulin resistance and thus the patient frequently became desparate or depressive and occasionally neglected her daily insulin injection. As Joslin et al. (1959) and Knowles (1970) pointed out, strict enforcement of diabetic treatment and relief of psychic stress in each patient may not clinically accelerate diabetic vascular lesions. In this respect, Murawski and his colleagues (1970) reported on a Quarter Century Victory Medalist who had had no sign of vascular disturbances even after long duration of diabetes and had shown significantly lower hypochondriasis scores in the character test of MMPI than nomedal patients did. Chazan and his group (1970) investigated longterm survival with an average of 36 years of duration of diabetes and pointed out that clinical symptoms of diabetic nephropathy were found only in $16 \%$, and that a large number of well-controlled cases executing 
regular physical exercise were included. It thus appears that not only the maintenance of good diabetic control but psychosocial factors and patients' character are responsible for the development of microangiopathy in diabetes mellitus.

There were two poorly-controlled cases of secondary diabetes in eleven cases in Table 4; they had progressive renal involvement. Whether diabetic glomerulosclerosis can occur associated with hemochromatosis or not is still a matter of controversy up to the present (MacDonald and Ireland 1964; Ireland et al. 1967a; Kreines et al. 1970), but the diabetic renal changes, if they are ascertained in such a case, may have possibly occurred secondary to metabolic defects of diabetes. On the other hand, about $25 \%$ of acromegaly is thought to be complicated with diabetes but the authors could not find a reported case of acromegaly with diabetic glomerulosclerosis. In the above-mentioned rare case of acromegaly with specific diabetic glomerulosclerosis (Case 1), improved diabetic state was transiently observed by means of ${ }^{60} \mathrm{Co}$ radiation but it was impossible to arrest the progress of glomerulosclerosis. Excessive secretion of growth hormone has been suggested to play a role in aggravating diabetes as well as in precipitating diabetic capillary disease (Lundbaek et al. 1970). Moreover, clinical evidence of reduced thickening of glomerular capillary basement membrane after pituitary albation was reported by Ireland and his colleagues (1967b). However, the changes of intrarenal vascular systems seem to have developed in their cases. It appears rather hopeless to improve the renal involvement in a more advanced stage. Beaumont and his colleagues (1971) assumed that excessive secretion of growth hormone caused enhanced lipolysis, inhibited glycolysis and consequently activated the sorbitol pathway leading to sorbitol accumulation in the tissues. Thus, they advanced a hypothesis that osmotic imbalance due to sorbitol accumulation mediates tissue damage and is ultimately responsible for the development of microangiopathy. Whether this hypothesis can be applied to all cases of primary diabetes is still to be examined.

In our own cases of diabetic glomerulosclerosis, those of progressive renal changes were generally accompanied by poorly controlled blood sugar levels, blood pressure and serum lipids. It is quite clear from the result that the effect of control of diabetes is closely associated with the progress of diabetic glomerulosclerosis. The view is also supported by the fact that in patients without progressive renal changes metabolic control of diabetes is rather easy. In our follow-up study, no amelioration of renal morphological changes was observed. It is perhaps fair to say from these results that diabetic glomerulosclerosis in overt diabetes is irreversible in contrast to retinopathy and neuropathy, although the three pathological conditions make a general concept of diabetic triopathy.

Gellman and his colleagues (1959) reported that clinical manifestations are usually less pronounced in the nodular lesions of Kimmelstiel and Wilson than in the diffuse type. In connection with their report, our own experiences are interesting, because some older diabetics with glomerulosclerosis of nodular type in Cases 8 and 11 exhibited relatively stable clinical state without impairment of 
renal function. All the patients of every age with diabetic glomerulosclerosis of nodular type will not necessarily take a distinctly progressive course. The reason why this characteristic pattern is observed in older diabetics remains obscure. In our own experience, however, diabetic glomerulosclerosis with IDGLs over 3 is generally associated with poor prognosis. For instances, the cases of multiple capillary thormboses in many glomeruli may immediately lead to glomerular insufficiency. Occasionally, however, incongruity of clinical and morphological renal features may appear, so that the prognosis of diabetic glomerulosclerosis is more reliably estimated with both clinical and morphological signs.

The outcome of juvenile diabetics with diabetic nephropathy, when the course of diabetes is protracted, is generally hopeless (Pollack et al. 1967). By contrast, in some older diabetics renal morphological changes are arrested in a rather stable condition (Distcherlein 1969). Not only chronically induced diabetic renal damages but also concomitant hypertensive vascular changes and intrarenal arteriosclerosis secondary to diabetes are responsible for the deterioration of renal function (Bjerkelund 1951). Mann and his colleagues (1949) reported that the average survival period in juvenile diabetics was only 6.4 years since the onset of nephrotic syndrome, whereas our own result agrees fairly well with that of Hatch and his colleagues (1961), who showed that most cases of diffuse and mixed renal lesion had died in about two years after confirmed diagnosis. In contrast to Caird's (1961) result that the expected survival rates of diabeties with proteinuria were not so bad as had generally been accepted, our data clearly indicate that diabetic glomerulosclerosis can advance almost steadily and that especially in juvenile diabetics it is sometimes impossible to arrest the progress by medical treatments. It appears necessary in the future to introduce surgical treatments such as renal transplantation or pituitary operation into the elinical practice. Repeated renal biopsies are considered one of the very suitable methods for determining the indication.

\section{Acknowledgment}

We are grateful to Prof. N. Suwa and Dr. S. Arai of the First Department of Pathology, Tohoku University School of Medicine, for their advice and instruction on histological examinations. Collaborations of Dr. T. Kubota of Nakadori Hospital in Akita Prefecture are deeply appreciated.

\section{References}

1) Beaumont, P., Hollows, F.C., Schofield, P.J. \& Williams, J.F. (1971) Growth hormone, sorbitol, and diabetic capillary disease. Lancet, 1, 579-581.

2) Bell, E.T. (1942) Renal lesions in diabetes mellitus. Amer. J. Path., 18, 744-745.

3) Bergstrand, A.F. \& Bucht, H. (1964) Electron microscopic studies of the kidney. In: Small Blood Vessel Involvement in Diabetes Mellitus, edited by M.D. Siperstein, A.R. Colwell \& K. Meyer, Amer. Inst. Biol. Scien., Washington, p. 65.

4) Berkman, J. \& Rifkin, H. (1966) Newer aspects of diabetic microangioapthy. Ann. Rev. Med., 17, 83-112.

5) Bjerkelund, C.J. (1951) Diabetic renal disease. Clinical studies of 1,335 diabetics 
treated in med. dept. A of the university hospital, Oslo 1930-1950. Acta med. scand., 139, 133-145.

6) Bloodworth, J.M.B. (1968) Endocrine Pathology, The Williams \& Wilkins Co. Baltimore, pp. 389-399.

7) Bloom, A. (1967) Relation of the complications of diabetes to the clinical state. Proc. Roy. Soc. Med., 60, 149-152.

8) Caird, F.I. (1961) Survival of diabetics with proteinuria. Diabetes, 10, 178-181.

9) Camerini-Davalos, R.A. (1966) Diagnosis of early asymptomatic diabetes from symposium of "Total care of diabetic patient from physiatrist's point of view". N.Y. St. J. Med., 66, I636-1642.

10) Camerini-Davalos, R.A., Opperman, W., MittI, R. \& Ehrenreich, T. (1970) Studies of vascular and other lesions in KK mice. Diabetologia, 6, 324-329.

11) Camerini-Davalos, R.A., Rees, S.B., Caulfield, J.B., Castaneda, O.L. \& Marble, A. (1964) Vascular changes in prediabetes. In: Small Blood Vessel Involvement in Diabetes Mellitus, edited by M.D. Siperstein, A.R. Colwell \& K. Meyer, Amer. Inst. Biol. Scien., Washington, p. 113.

12) Colwell, A.R. (1964) Relation of small blood vessel complications to treatment of diabetes: a review. In: Small Blood Vessel Involvement in Diabetes Mellitus, edited by M.D. Siperstein, A.R. Colwell \& K. Meyer, Amer. Inst. Biol. Scien., Washington, p. 253.

13) Chazan, B.I., Balodimos, M.C., Ryan, J.R. \& Marble, A. (1970) Twenty five to forty five years of diabetes with and without vascular complications. Diabetologia, 6, 565-569.

14) Daysog, A., Jr. Dobson, H.L. \& Brennan, J.C. (1961) Renal glomerular and vascular lesions in prediabetes and in diabetes mellitus: A study based on renal biopsies. Ann. intern. Med., 54, 672-684.

15) Ditscherlein, G. (1969) Nierenveränderungen bei Diabetikern. Veb Gutstav Fischer Verlag Jena, p. 130.

16) Ellenberg, M. (1962) Diabetic nephropathy without manifest diabetes. Diabetes, 11, 197-201.

17) Fujita, A. \& Iwatake, D. (1931) Bestimmung des echten Blutzuckers ohne Hefe. Biochem. Ztschr., 242, 43-60.

18) Fukuhara, N. (1968) Histometrical studies on the kidneys in diabetes mellitus. Tohoku J. exp. Med., 95, 15-33.

19) Gellman, D.D., Pirani, O.L., Soothill, J.F., Muehrcke, R.C., Maduros, W. \& Kark, R.M. (1959) Structure and function in diabetic nephropathy. The importance of diffuse glomerulosclerosis. Diabetes, 8, 251-256.

20) Goto, Y. \& Fukuhara, N. (1968) Cause of death in 933 diabetic autopsy cases. $J$. Jap. Diab. Soc. (Jap.), 11, 197-206.

21) Harrington, A.P., Hare, H.G., Chambers, W.N. \& Valtin, H. (1966) Nodular glomerulosclerosis in a nondiabetic patient. New Engl. J. Med., 275, 206-208.

22) Hatch, F.E., Watt, M.F., Kramer, N.C., Parrish, A.E. \& Howe, J.S. (1961) Diabetio glomerulosclerosis. A long-term follow-up study based on renal biopsies. Amer. J. Med., 31, 216-230.

23) Ireland, J.T., Patnaik, B.K. \& Duncan, L.J.P. (1967a) Glomerular ultrastructure in secondary diabetics and normal subjects. Diabetes, 16, 628-635.

24) Ireland, J.T., Patnaik, B.K. \& Duncan, L.J.P. (1967b) Effect of pituitary ablation on the renal and arteriolar and glomerular lesions in diabetes. Diabetes, 16, 736-642.

25) Johansen, K. (1969) Diabetic angiopathy in a patient with normal glucose tolerance and plasma insulin response. Amer. J. Med., 47, 487-491.

26) Johnsson, S. (1960) Retinopathy and nephropathy in diabetes mellitus comparison of the effects of two forms of treatment. Diabetes, 9, 1-8.

27) Joslin, E.P., Root, H.F., White, P. \& Marble, A. (1959) The Treatment of Diabetes Mellitus. 10th Ed. Lea \& Febiger, Philadelphia, p. 238.

28) Kimmelstiel, P. \& Wilson, C. (1936) Intercapillary lesions in the glomeruli of the 
kidney. Amer. J. Path., 12, 83-98.

29) Knowles, H.C., Jr. (1970) Control of diabetes and the progression of vasenlar disease. In: Diabetes Mellitus: Theory and Practice, edited by M. Ellenberg \& $\mathbf{H}$. Rifkin, McGrow-Hill Book Co, A Blakiston Pub., p. 666.

30) Kreines, K., Kim, O. \& Knowles, H.C. (1970) Glomerulosclerosis, hemochromatosis, and diabetes mellitus. Amer. J. clin. Path, 54, 47-62.

31) Kuzuya, N. \& Kosaka, K. (1970) Diabetes in Japan: Diabetes Mellitus in Asia, Excerpta Medica edited by S. Tsuji \& M. Wada, p. 13.

32) Lundbaek, K., Christensen, N.J., Jensen, V.A., Johansen, K., Olsen, T.S., Hansen, A. P., Ørskov, H. \& Østerby, R. (1970) Diabetes, diabetic angiopathy, and growth hormone. Lancet, 2, 13l-133.

33) MacDonald, M.K. \& Ireland, J.T. (1964) The glomerular lesion in idiopathic and secondary diabetes. In: Ciba Foundation Colloquia on Endocrinology Vol. 15, The aetiology of diabetes mellitus and its complications edited by M.P. Cameron \& M. O'Connor, J. \& A. Churchill Ltd., London, p. 301.

34) Mann, G.V., Gardner, C.\& Root, H.F. (1949) Clinical manifestations of intercapillary glomerulosclerosis in diabetes mellitus. Amer. J. Med., 7, 3-14.

35) Marble, A. (1965) Relation of control of diabetes to vascular sequelae. Med. Clin. N. Amer., 49, 1137-1145.

36) Marble, A. (1967) Angiopathy in diabetes: An unsolved problem (The Banting memorial lecture 1967). Diabetes, 16, 825-838.

37) Murawski, B.J., Chazan, B.I., Balodimos, M.C. \& Ryan, J.R. (1970) Personality patterns in patients with diabetes mellitus of long duration. Diabetes, 19, 259-263.

38) Osterby, R. (1971) Diabetic nephropathy. In: Diabetes Mellitus: Diagnosis and Treatment, Vol. UI, edited by S.S. Fajans \& K.E. Sussman, Amer. Diab. Ass. Inc., New York, p. 333.

39) Pollack, A.A., MLcGurl, T.J. \& Macintyre, N. (1967) Diabetes mellitus. A review of mortality experience. Arch. intern. Med., 119, 161-163.

40) Rikfin, K. \& Berkman, J. (1970) Diabetes and the kidney. In: Diabetes Mellitus: Theory and Practice, edited by M. Ellenberg \& H. Rikfin, McGrow-Hill Book Co. A Blakiston Pub., p. 848.

41) Root, H.F. (1965) Prognosis in diabetes. Med. Clin. N. Amer, 49, 1147-1161.

42) Shirai, T., Welsh, G.W. \& Sims, E.A.H. (1967) Diabetes in the Chinese hamster II. The evolution of renal glomerulopathy. Diabetologia, 3, 266-286.

43) Siperstein, M.D., Unger, R.H. \& Madison, L.L. (1968) Studies of muscle capillary basement membanes in normal subjects, diabetic, and prediabetic patients. $J$. clin. Invest., 47, 1973-1999.

44) Suwa, N. \& Yamagata, S. (1965) Correlation of diabetic glomerulosclerosis with clinical states. J. Jap. Diab. Soc. (Jap.), 8, 139-144. 